\title{
Mesopore Bioglass/Silk Composite Scaffolds for Bone Tissue Engineering
}

\author{
Chengtie $\mathrm{Wu}$ and Yin Xiao \\ Queensland University of Technology \\ Australia
}

\section{Introduction}

In the past 20 years, mesoporous materials have been attracted great attention due to their significant feature of large surface area, ordered mesoporous structure, tunable pore size and volume, and well-defined surface property. They have many potential applications, such as catalysis, adsorption/separation, biomedicine, etc. [1]. Recently, the studies of the applications of mesoporous materials have been expanded into the field of biomaterials science. A new class of bioactive glass, referred to as mesoporous bioactive glass (MBG), was first developed in 2004. This material has a highly ordered mesopore channel structure with a pore size ranging from 5-20 nm [1]. Compared to non-mesopore bioactive glass (BG), MBG possesses a more optimal surface area, pore volume and improved in vitro apatite mineralization in simulated body fluids [1,2]. Vallet-Regí et al. has systematically investigated the in vitro apatite formation of different types of mesoporous materials, and they demonstrated that an apatite-like layer can be formed on the surfaces of Mobil Composition of Matters (MCM)-48, hexagonal mesoporous silica (SBA-15), phosphorousdoped MCM-41, bioglass-containing MCM-41 and ordered mesoporous MBG, allowing their use in biomedical enineering for tissue regeneration [2-4]. Chang et al. has found that MBG particles can be used for a bioactive drug-delivery system [5,6]. Our study has shown that MBG powders, when incorporated into a poly (lactide-co-glycolide) (PLGA) film, significantly enhance the apatite-mineralization ability and cell response of PLGA films. compared to BG [7]. These studies suggest that MBG is a very promising bioactive material with respect to bone regeneration. It is known that for bone defect repair, tissue engineering represents an optional method by creating three-dimensional (3D) porous scaffolds which will have more advantages than powders or granules as 3D scaffolds will provide an interconnected macroporous network to allow cell migration, nutrient delivery, bone ingrowth, and eventually vascularization [8]. For this reason, we try to apply MBG for bone tissue engineering by developing MBG scaffolds. However, one of the main disadvantages of MBG scaffolds is their low mechanical strength and high brittleness; the other issue is that they have very quick degradation, which leads to an unstable surface for bone cell growth limiting their applications.

Silk fibroin, as a new family of native biomaterials, has been widely studied for bone and cartilage repair applications in the form of pure silk or its composite scaffolds [9-14]. Compared to traditional synthetic polymer materials, such as PLGA and poly(3- 
hydroxybutyrate-co-3-hydroxyvalerate) (PHBV), the chief advantage of silk fibroin is its water-soluble nature, which eliminates the need for organic solvents, that tend to be highly cytotoxic in the process of scaffold preparation [15]. Other advantages of silk scaffolds are their excellent mechanical properties, controllable biodegradability and cytocompatibility [15-17]. However, for the purposes of bone tissue engineering, the osteoconductivity of pure silk scaffolds is suboptimal. It is expected that combining MBG with silk to produce MBG/silk composite scaffolds would greatly improve their physio-chemical and osteogenic properties for bone tissue engineering application. Therefore, in this chapter, we will introduce the research development of MBG/ silk scaffolds for bone tissue engineering.

\section{Preparation, characterization, physio-chemistry and biological property of MBG/silk composite scaffolds}

In the section, we will introduce the novel development of MBG/silk composite scaffolds prepared by two methods for bone tissue engineering. One is that we will use silk-modified MBG scaffolds to enhance mechanical, biological and drug-delivery properties for bone regeneration application; the other is to incorporate MBG powders into silk scaffolds to improve their physio-chemistry and in vivo osteogenesis.

\subsection{Silk-modified MBG scaffolds}

\subsubsection{Composition optimization and characterization of silk-modified MBG scaffolds}

To prepare and optimize MBG scaffolds, a series of MBG scaffolds with varied composition (molar composition: 100Si; 90Si-5Ca-5P; 80Si-15Ca-5P and 70Si-25Ca-5P) have been prepared by co-template method of $\mathrm{P} 123\left(\mathrm{EO}_{20}-\mathrm{PO}_{70}-\mathrm{EO}_{20}\right)$ and polyurethane sponges (PUS), in which P123, as the template of mesopore formation, creates well-ordered mesoporous channels (around $5 \mathrm{~nm}$ ) and PUS, as the template of large pores, produces hierarchically large pores (around 200-400 $\mu \mathrm{m}$ ) (Figure 1). Our study has shown that MBG with the composition of 80Si-15Ca-5P has optimized bioactivity among four scaffolds [18]. Therefore, in this study, MBG (80Si-15Ca-5P) was selected for the further study.
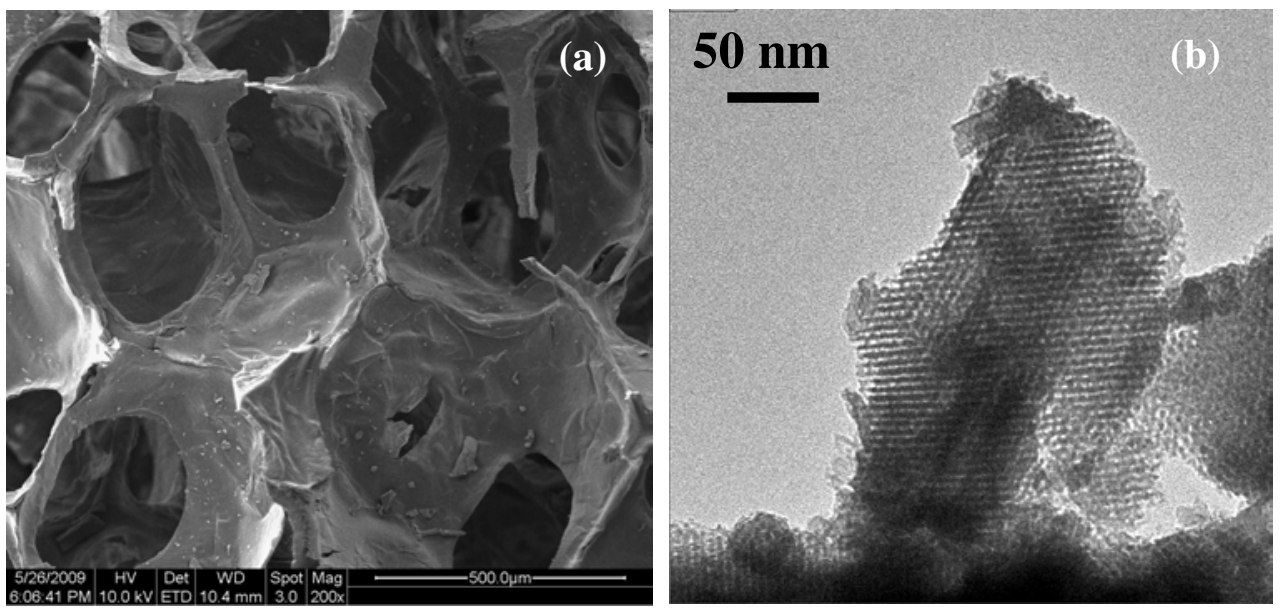

Fig. 1. SEM (a) and TEM (b) images for the prepared MBG scaffolds. 
Silk-modified MBG scaffolds were prepared by dip-coating silk fibroin solution (wt. $2.5 \%$ and $5 \%$ ) on the surface of scaffold pore walls with the cross linking of ethanol. After modification, a smooth silk film had formed on the surface of pore wall (Fig. 2b). Silkmodified MBG scaffolds showed a more uniform and continuous pore network (Fig. 2b) compared to unmodified MBG scaffolds with numerous collapsed and un-continuous pore networks due to their brittle nature (Fig. 2c). Silk-modified MBG scaffolds had a highly porous structure with the large-pore size of $400 \mu \mathrm{m}$ and maintained high porosity $(95 \%)$. These characteristics indicate that silk-modified MBG scaffolds satisfy the requirements of pore structure architecture for cell and blood vessel ingrowth and nutrient supply [8].
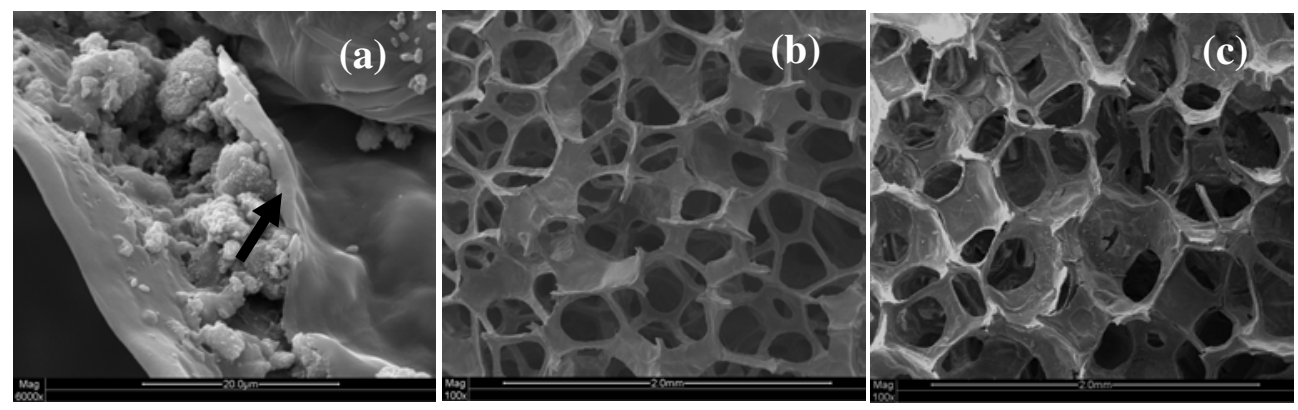

Fig. 2. SEM images for the formed silk layer (see arrow) (a), silk-modified MBG scaffolds (b) and un-modified MBG scaffolds (c) [19].

\subsubsection{Physio-chemistry and biological property of silk-modified MBG scaffolds}

The concentration of silk fibroin plays an important role to influence the compressive strength of MBG scaffolds. The compressive strength of pure MBG scaffolds was estimated to be $60 \mathrm{kPa}$. Silk modification significantly improved the compressive strength of MBG scaffolds, which increases to $120 \mathrm{kPa}$ for $2.5 \%$ Silk-MBG scaffolds and $250 \mathrm{kPa}$ for $5.0 \%$ SilkMBG scaffolds, a 100 and 300\% increase, respectively (Fig. 3). There are two possible explanations as to why silk-modification improves the mechanical properties of the MBG scaffolds [19]. (1) Silk modification may induce a more uniform and continuous pore network within the MBG scaffolds, which, due to their natural brittleness, would otherwise have collapsed pore networks and micro-defects (micropores) and which contributes to their low mechanical strength; or (2) silk, which has greater mechanical strength than any other traditional polymer [15], may form an intertexture within the MBG scaffolds, linking the inorganic phase together and, in effect, reinforce the scaffolds [20].

By comparison, the compressive strength of hydroxyapatite and $\beta$-Tricalcium phosphate is only $30 \mathrm{kPa}[21]$ and $50 \mathrm{kPa}$ [22], when their porosity is greater than $90 \%$. The compressive strength of spongy bone (not the strut) is in the range of 0.2-4 MPa [23]. Therefore, the silk-modified MBG scaffolds fall within this range and therefore mimic that of cancellous bone. 


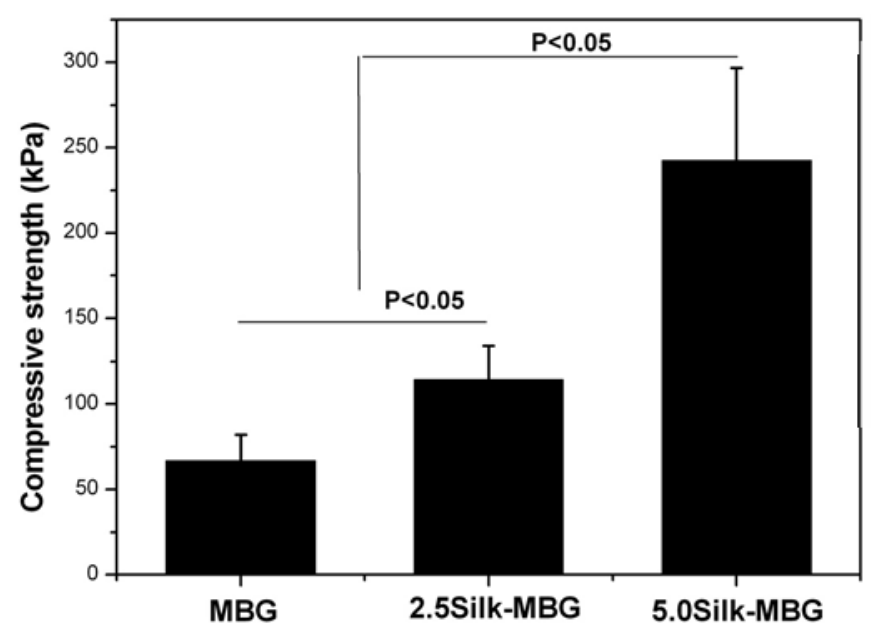

Fig. 3. The effect of silk concentration on the mechanical strength of MBG scaffolds [19].

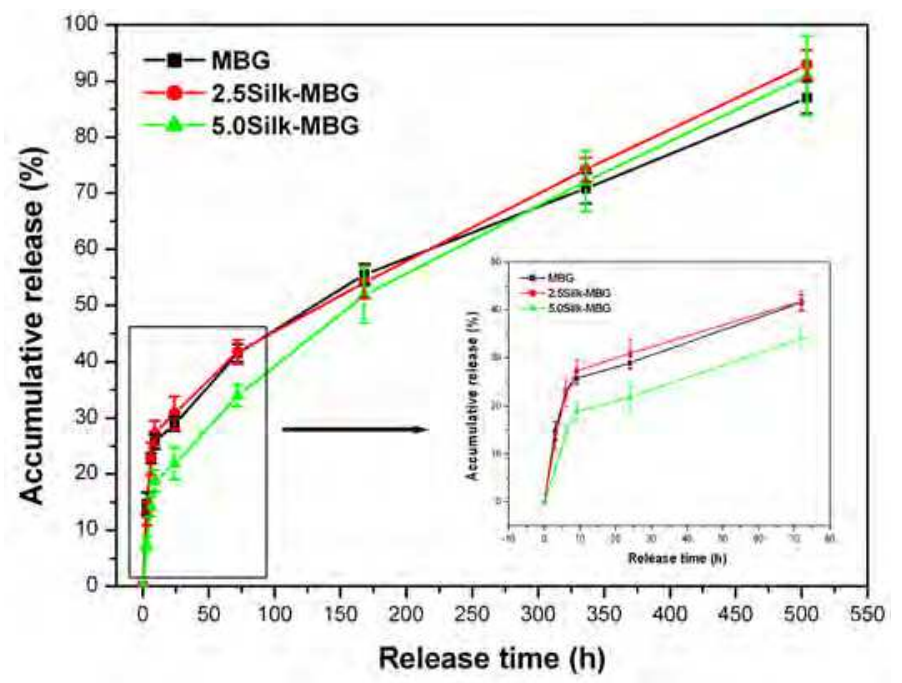

Fig. 4. Drug release from silk-modified and unmodified of MBG scaffolds [19].

Drug delivery represents another major challenge for scaffolds applicable for bone tissue engineering. In traditional scaffolds it was very difficult to combine the function of drug delivery due to the absence of a nano-pore structure. Due to the existence of well-ordered mesoporous structure in the MBG scaffolds, they can be used for the drug carrier. Dexamethasone can be easily loaded in the matrix of scaffolds by a simple soaking method. 
The 5.0\%Silk-MBG scaffolds had a decreased burst release compared to MBG scaffolds, and maintained a sustained release (Fig. 4). The most likely explanation for this is that the $5 \%$ silk solution forms a relatively dense silk film on the surface of pore walls which slows the drug release; however, over time the silk will begin to degrade and its effect on the release kinetics will therefore abate. This was evident by the fact that there was no discernible difference of the drug-release rate of the 5.0\%Silk-MBG scaffold compared to the $2.5 \%$ Silk-MBG and the MBG scaffolds (Fig. 4). Further study has shown that after the drug release in phosphate buffer solution (PBS), a thin Ca-P layer of micro-particles was found to have been deposited on the surface of pore walls (Fig. 5). The formed Ca-P layer, one the one hand, will have an inhibitory effect on drug release [24]; On the other hand, it is indicated that silk-modified MBG scaffolds maintained the bioactivity of the surface chemistry as the Ca-P formation ability was regarded as one of important factor for bioceramics according to Kokubo's view [25].

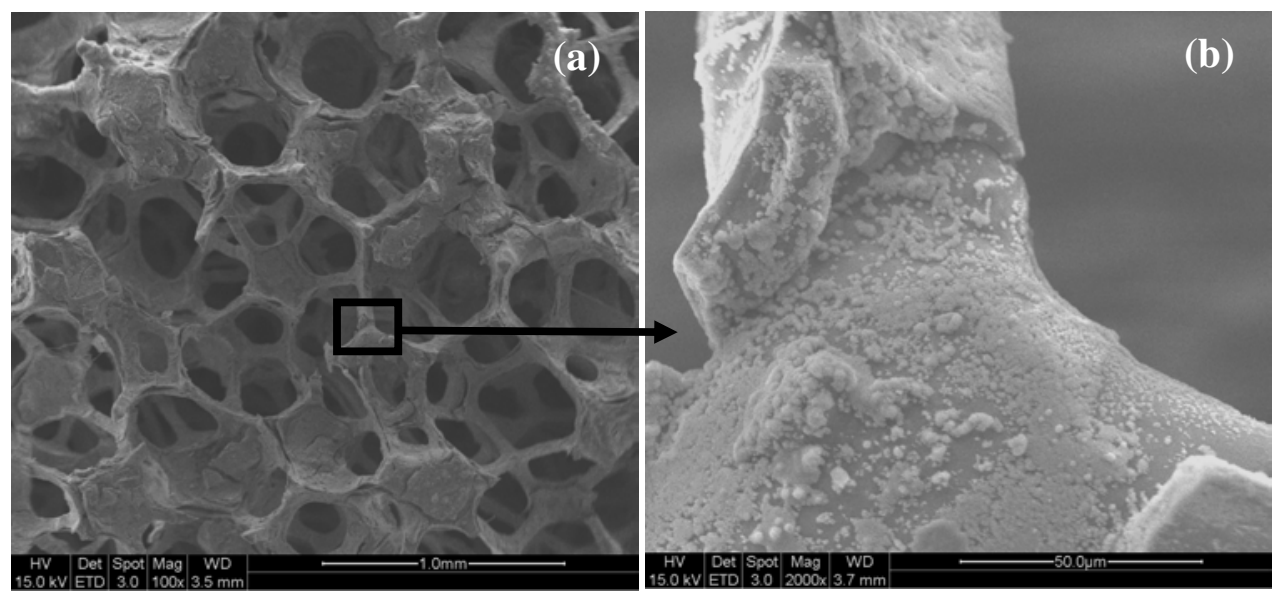

Fig. 5. SEM images for silk-modified MBG scaffolds after drug release in PBS.

The biological properties of silk-modified MBG scaffolds were further investigated by evaluating the attachment, proliferation, differentiation and bone cell-relative gene (alkaline phosphatase activity (ALP) and osteocalcin (OCN)) expression of bone marrow stromal cells (BMSC). After 1 day of culture, BMSCs were attached to the surface of the pore walls in all three types of scaffolds (Fig. 6). There was no obvious difference in the cell numbers and morphology of the attached cells among the scaffold types after one day. After 7 days, however, the density of BMSCs on 2.5\%Silk-MBG and 5.0Silk-MBG scaffolds was higher than that of pure MBG scaffolds, the BMSCs on the $5.0 \%$ Silk-MBG scaffolds eventually reaching confluence. High magnification images show that BMSCs on 5.0\%Silk-MBG scaffolds had a more spread out morphology than those on pure MBG scaffolds and that the cells had close contact with the pore walls of 5.0\%Silk-MBG scaffolds (Fig. 6).

Silk modification significantly improved the proliferation and ALP activity of BMSCs on MBG scaffolds. At day 1, the number of cells on the silk-modified MBG scaffolds were comparable with that of pure MBG scaffolds (Fig. 7a), whereas by day 7, the number of cells on the silk-modified MBG scaffolds was significantly higher than that on the pure MBG scaffolds $(\mathrm{p}<0.05)$. ALP activity was used as an early marker of BMSC differentiation on scaffolds. After 7 days of culture, the ALP activity of the cells on all three scaffold types was 
roughly equal (Fig 7b); however, after 14 days the ALP activity of BMSCs in the $5.0 \%$ SilkMBG scaffolds was greater than that of the other two scaffold types (Fig. 7b). The osteoblastic differentiation was further assessed by the mRNA expression of ALP and OCN using RT-qPCR method. There was an upregulation of the osteogenic marker genes of OCN and ALP after the modification of MBG scaffolds by silk (Fig. 8).
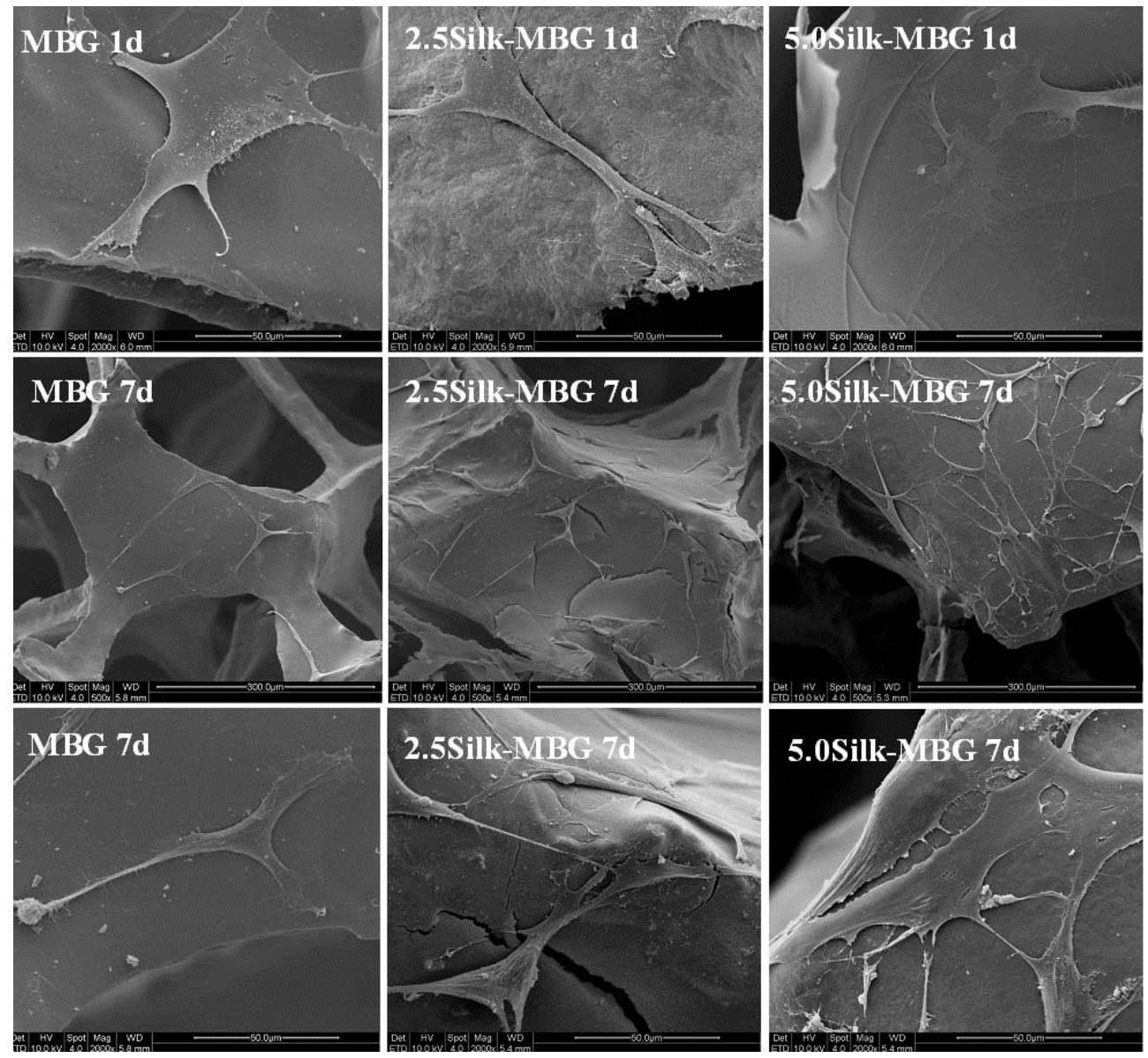

Fig. 6. The morphology of bone marrow stromal cells on the silk-modified and unmodified MBG scaffolds after 1 and 7 days of culture [19].

From the results above, it is indicated that that silk modification of MBG scaffolds had a positive effect on the attachment, proliferation and differentiation of BMSCs [19]. Generally, the ionic environment and material surface are two main factors which influence the interaction of cells and biomaterials [7,26-29]. In this study, silk modification did not create any significant effect on either ionic release or weight loss of MBG scaffolds. It has been speculated that the ionic environment and $\mathrm{pH}$ value of culture media may not be the most important factors affecting the cell response. Therefore, there is a reasonable hypothesis that 

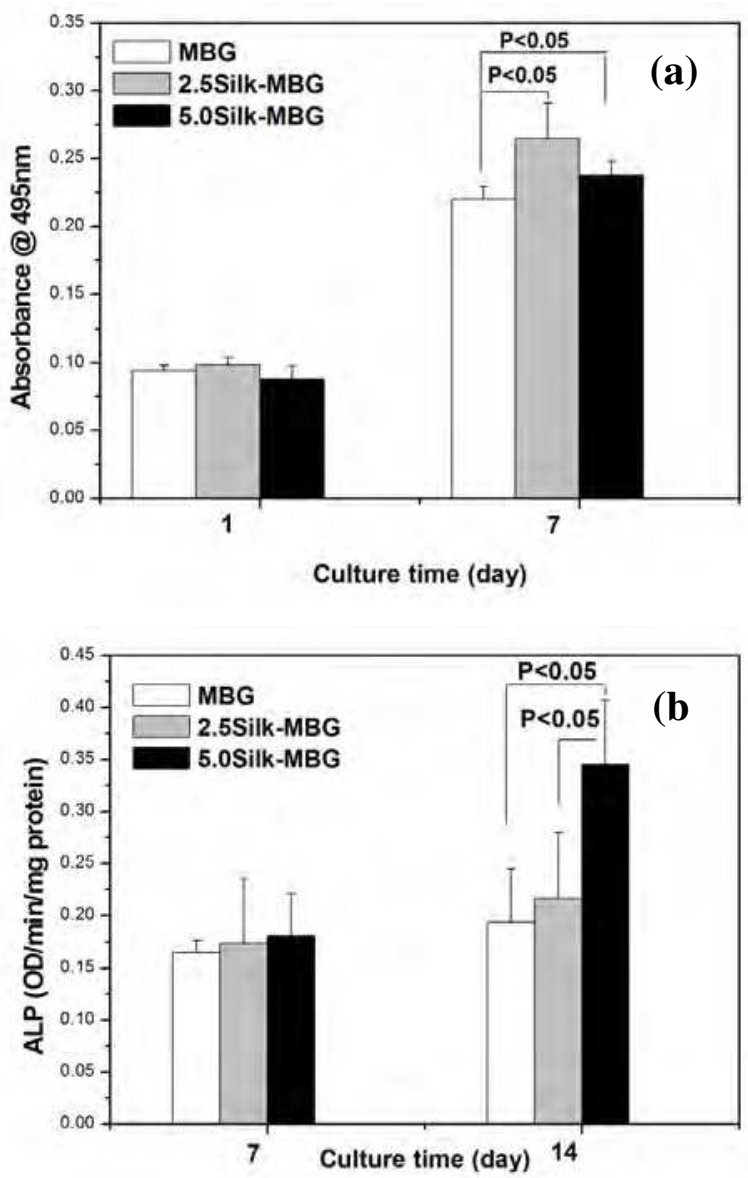

Fig. 7. The proliferation (a) and ALP activity of bone marrow stromal cells on the silkmodified and unmodified MBG scaffolds [19].

the silk itself may be responsible for enhancing BMSC proliferation and differentiation. It is known that, generally, the stable surface of biomaterials enhances cell attachment and proliferation, compared to the unstable surface of biomaterials which have a higher rate of dissolution [28]. MBG scaffolds have a high rate of degradation leaving their surface relatively unstable, and this may affect cell growth. The silk used in this study is the relatively stable fibroin, which consists of a $\beta$-sheet structure. When applied to the MBG scaffolds this silk may provide a relatively stable surface interface to support BMSC proliferation and differentiation. It has been reported that silk-functionalized titanium surfaces can enhance osteoblast functions [30,31], and also that silk modification of poly (D,L-lactic acid) improves ostoblast differentiation [32]. Although the mechanisms underlying this stimulatory effect on cell functions remains unclear, the explanation may be related to the interaction with specific chemical groups in silk, such as amino acids [15]. 

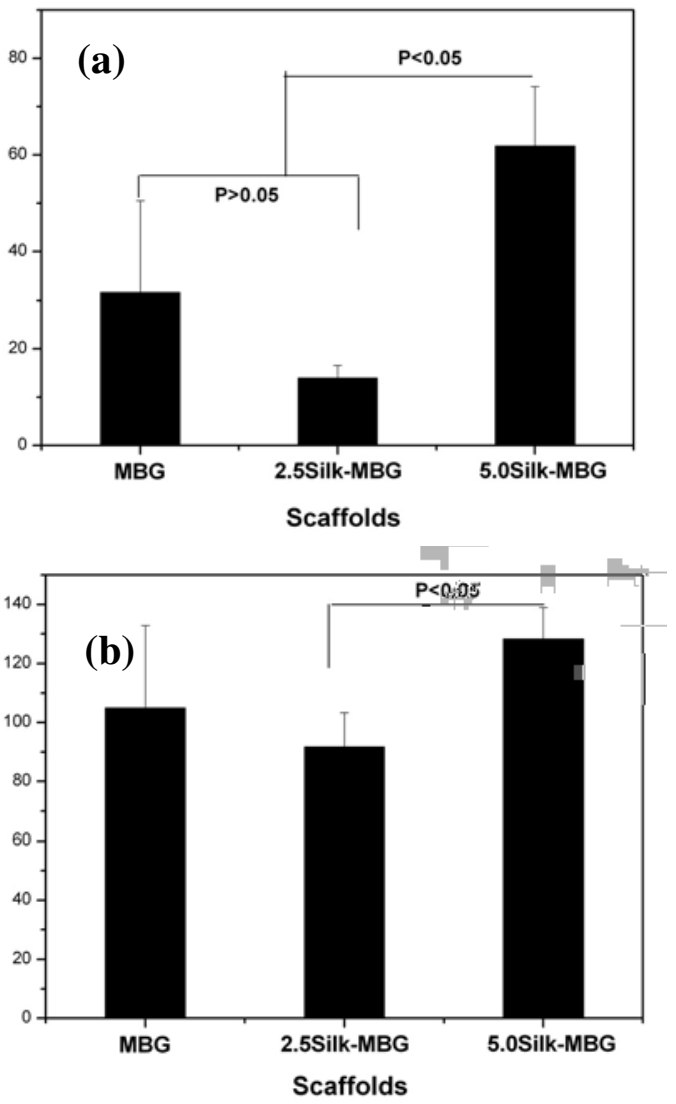

Fig. 8. The bone-relative gene expression of OCN (a) and ALP (b) of bone marrow stromal cells on the silk-modified and unmodified MBG scaffolds [19].

\subsection{MBG powders-incorporated silk scaffolds}

\subsubsection{Preparation, characterization and physio-chmistry of MBG-incorporated silk} scaffolds

MBG powders (molar composition: 80Si-15Ca-5P) with a particle size lower than $45 \mu$ mere synthesized by an evaporation-induced self-assembly process according to the publications [7]. The obtained MBG powders possess well-ordered mesoporous structure (see Fig. 9a). Non-mesoporous bioglass (BG) powders with same composition were synthesized for the control materials (Fig. 9b). The surface area and pore volume of MBG are about $400 \mathrm{~m}^{2} / \mathrm{g}$ and $0.5 \mathrm{~cm}^{3} / \mathrm{g}$, respectively, which are obviously higher than those of BG $\left(57 \mathrm{~m}^{2} / \mathrm{g}\right.$ for surface area, $0.09 \mathrm{~cm}^{3} / \mathrm{g}$ for pore volume).

Porous MBG/silk scaffolds with $10 \%$ MBG (w/w) were fabricated using a freeze-drying method. Pure silk and BG/silk scaffolds were prepared by same method for the control materials. The silk, MBG/silk and BG/silk scaffolds were highly porous (Fig. 10), with near identical porosities, $78 \%, 76 \%$ and $76 \%$, respectively. The pure silk scaffolds had a flat pore 

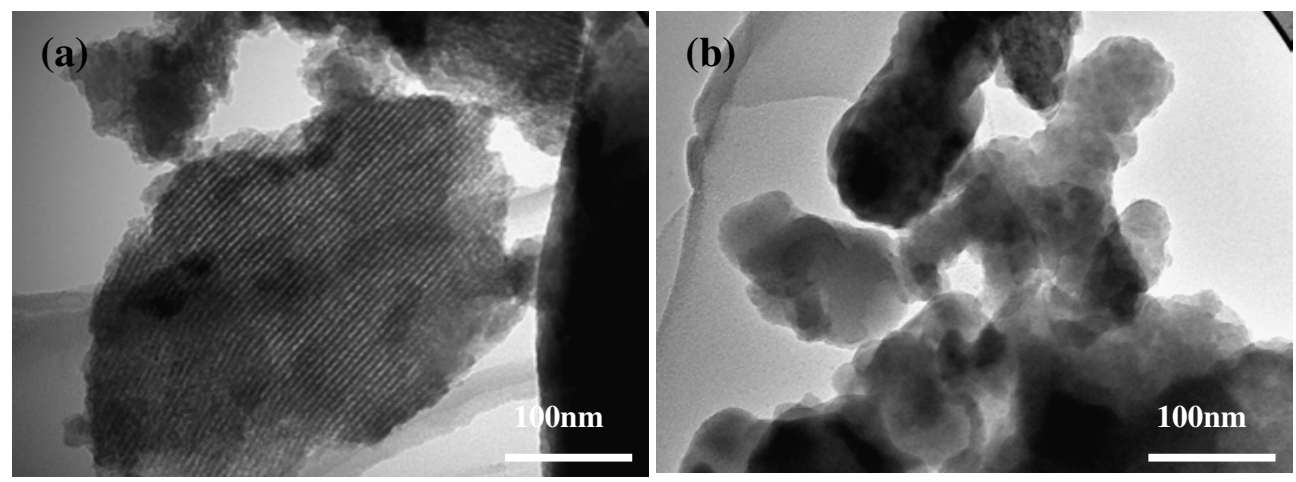

Fig. 9. TEM images of MBG (a) and BG (b) powders [7].

morphology (Fig. 10a), whereas the MBG or BG composite scaffolds had a more open pore morphology (Fig. 10b and c) compared to the silk scaffolds. The pore size of the pure silk scaffolds ranged from several tens to one hundred micrometers; the pore size of the composite scaffolds is larger than that of pure silk scaffolds [33].

The compressive strength and modulus of MBG/silk scaffolds were $420 \mathrm{kPa}$ and $0.70 \mathrm{MPa}$, respectively, figures that were comparable with those of pure silk scaffolds and greater than those of BG/silk scaffolds ( $300 \mathrm{kPa}$ for compressive strength and $0.5 \mathrm{MPa}$ for modulus). It is speculated that the incorporation of BG particles into silk scaffolds may destroy the inner structure of silk and lead to the detrimental effect of the mechanical strength of silk scaffolds. Although MBG particles may also destroy the inner structure of silk, however, MBG has high surface area and pore volume, and parts of silk solution may enter into the nanopores of MBG during preparation, which leads to a strong bond between MBG particles and silk after freeze-drying. Thus, the incorporation of MBG into silk will not decrease the mechanical strength of silk scaffolds [33].

The apatite-mineralization ability and ion release of scaffolds were carried out using acellular simulated body fluids (SBF). The morphology of the three scaffold species, after soaking in SBF, is shown in Figure 11. There was no apatite particles deposit visible on the pore wall surfaces for pure silk and BG/silk scaffolds (Fig. 11a and b). However, a layer of apatite microparticles formed on the pore wall of MBG/silk scaffolds (Fig. 11c) and at higher magnification apatite was seen as nano-sized particles (Fig. 11d). EDS analysis revealed the ratio of $\mathrm{Ca} / \mathrm{P}$ of the apatite to be 2.3 [33]. Apatite mineralization of silicate materials, such as $\mathrm{CaSiO}_{3}$ ceramics, $45 \mathrm{~S} 5$ bioglass, etc. is thought to be an important phenomenon in the chemical interactions between the implant materials and the bone tissue, which ultimately affects the in vivo osteogenesis of the bone grafting materials [34-36]. In this study, MBG/silk scaffolds had an obvious apatite mineralization in SBF, whereas neither BG/silk nor pure silk scaffolds induced apatite mineralization. This suggests that MBG/silk scaffolds have an improved "in vitro bioactivity", a term that has been used in previous studies $[25,37,38]$.

There was a sustained release of Si ions from both the MBG/silk and BG/ silk scaffolds, even across an extended period of soaking and the MBG/silk scaffolds had a faster rate of Si ion release than BG/silk scaffolds. The $\mathrm{pH}$ value of SBF with MBG/silk scaffolds stayed within a range of 7.25-7.5 throughout the 6 weeks of soaking. The $\mathrm{pH}$ values of the pure silk and 

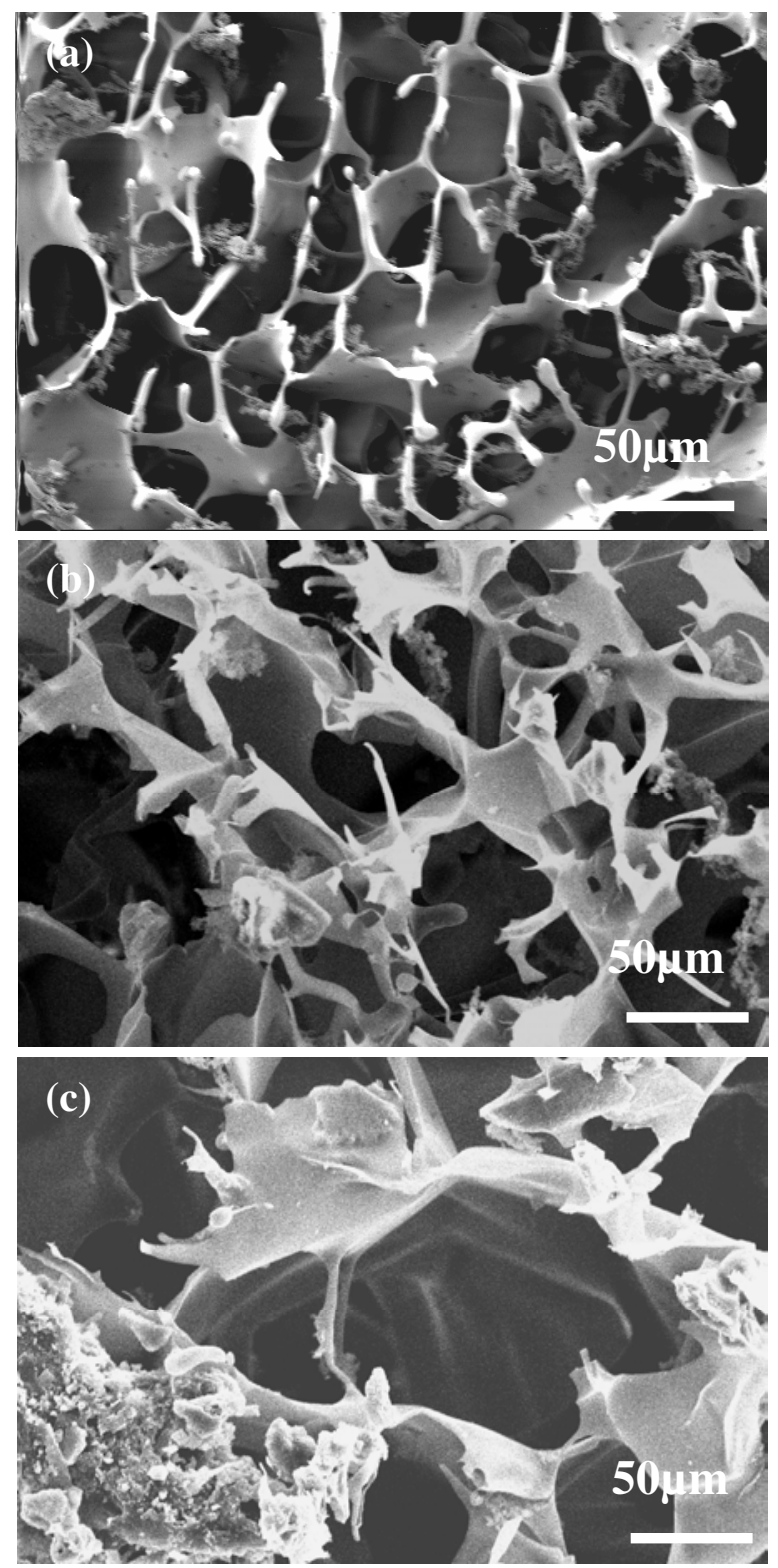

Fig. 10. Surface morphology of porous silk (a), MBG/silk (b) and BG/silk (c) scaffolds.

BG/silk scaffolds resulted in a slight decreased in SBF, varying from 7.1 to 7.4 [33]. Therefore, it is very obvious that the incorporation of MBG powders into silk scaffolds significantly improved their physio-chmestry. Further study for the effect of in vivo osteogenesis has been further investigated in the following section. 


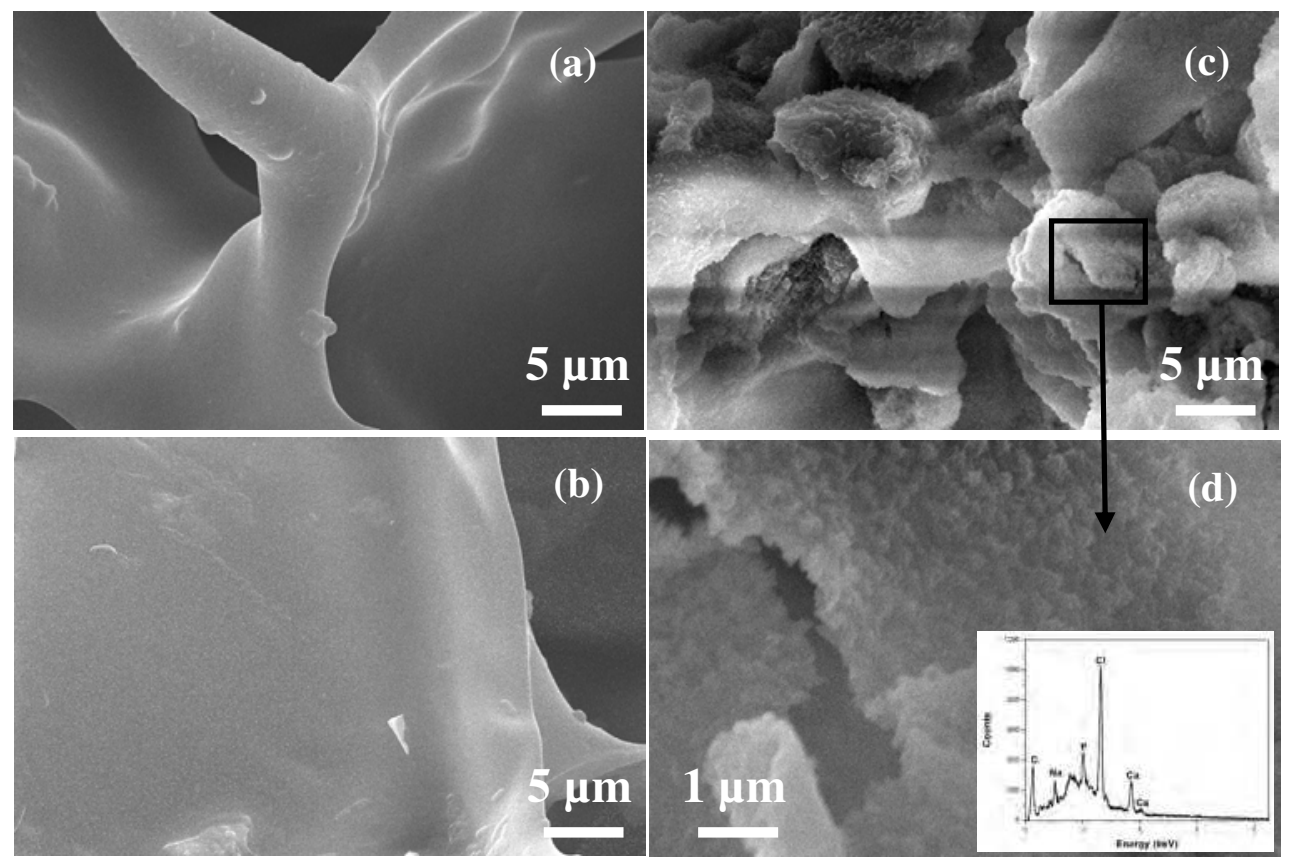

Fig. 11. SEM and EDS analysis silk (a), BG/silk (b) and MBG/silk (c and d) scaffolds after soaking in simulated body fluids for 7 days [33].

\subsubsection{The in vivo osteogenesis of MBG-incorporated silk scaffolds}

To further investigate the in vivo osteogenesis of MBG-incorporated silk scaffolds, the scaffolds were implanted into calvarial defects in adult severe combined immunodeficient (SCID) mice and the degree of in vivo osteogenesis was evaluated by micro-computed tomography $(\mu \mathrm{CT})$, hematoxylin and eosin $(\mathrm{H} \& \mathrm{E})$ and immunohistochemistry (type I collagen) analyses.

Both MBG/silk and BG/silk scaffolds clearly showed better bone repair ability than pure silk scaffolds. The defects implanted with MBG/silk scaffolds had been completely filled with new bone mineral tissues (Fig. 12a). The BG/silk scaffolds also induced new bone formation in the defects (Fig. 12b). However, the skull defects implanted with pure silk scaffolds revealed little mineralized tissues around the border and no new bone formation at all in the middle of the defects (Fig. 12c). Quantitative analysis from $\mu \mathrm{CT}$ data showed that the mineralized tissue volume for MBG composite was a little higher than that of BG composite. The volume of mineralized tissue for silk, MBG/silk and BG/silk scaffolds was 2.5, 7.0 and $6.1 \mathrm{~mm}^{3}$, respectively (Fig. 12d) [33].

New bone filled most of the MBG/silk scaffolds from the edge to the center and formed a continuous plate of bone area (Fig. 13a and b). Most of MBG/silk scaffolds had been degraded (Fig. 13a). In the BG/ silk scaffolds the majority of the new bone was located in the periphery, with some bone islands forming centrally. There was only limited degradation of the BG/silk scaffolds (Fig. 13c and d). In the skull defects implanted with pure silk scaffolds there was no evidence of bone formation. 

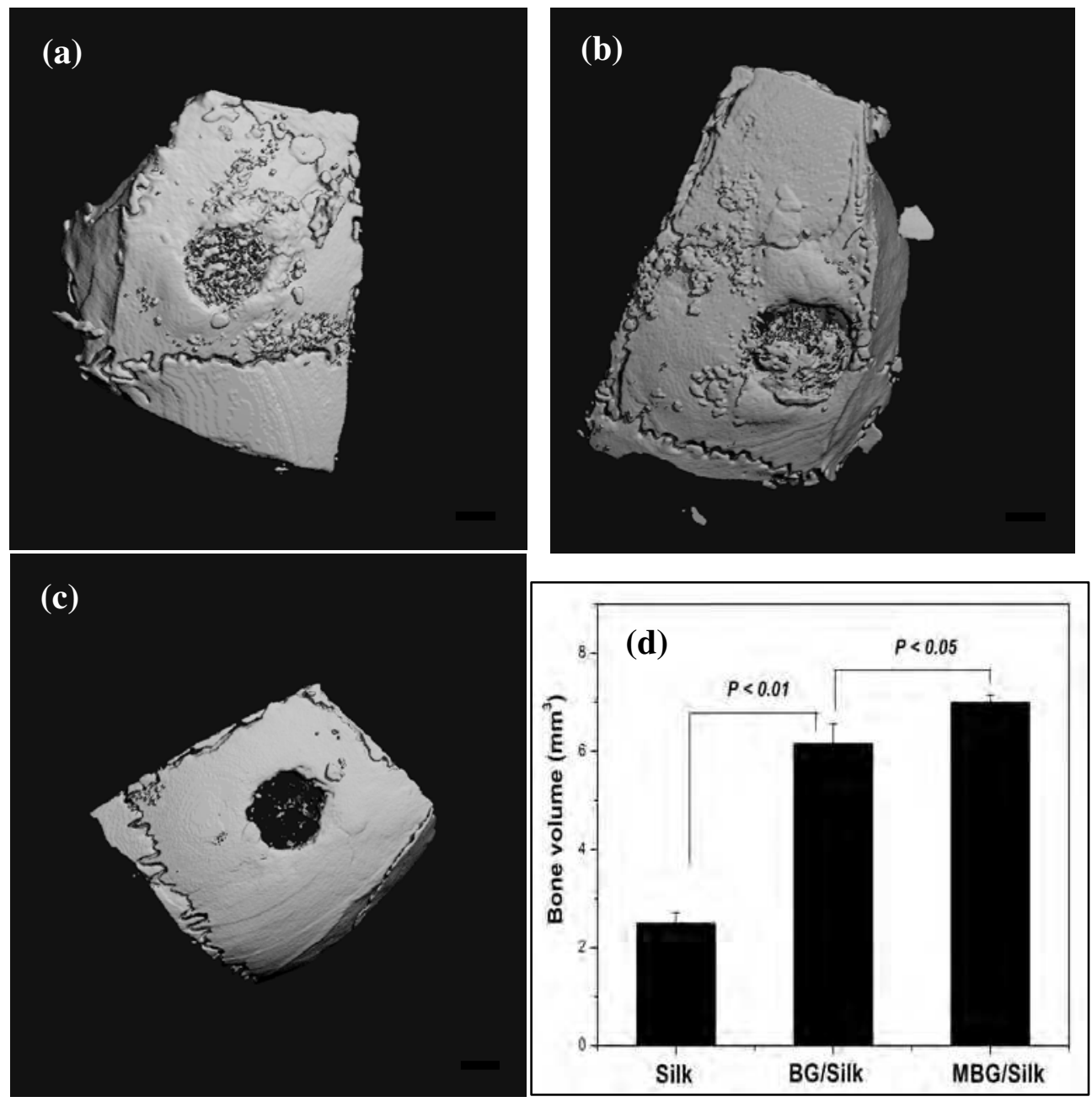

Fig. 12. Micro-CT analysis for the in vivo bone formation of MBG/silk (a), BG/ silk (b), silk (c) scaffolds, and new bone volume (d) after implanted in calvarial defects of SCID mice for 8 weeks [33].

Immunohistochemical analysis revealed type I collagen (COL1) expression in the de novo bone in both MBG/silk and BG/silk scaffolds (Fig. 14); there was certainly slightly strong COL1 expression in the bone matrix of the MBG/silk scaffolds (Fig. 14a and b) and this expression was discernibly stronger compared to that in the BG/silk scaffolds (Fig. 14c and d) [33]. 

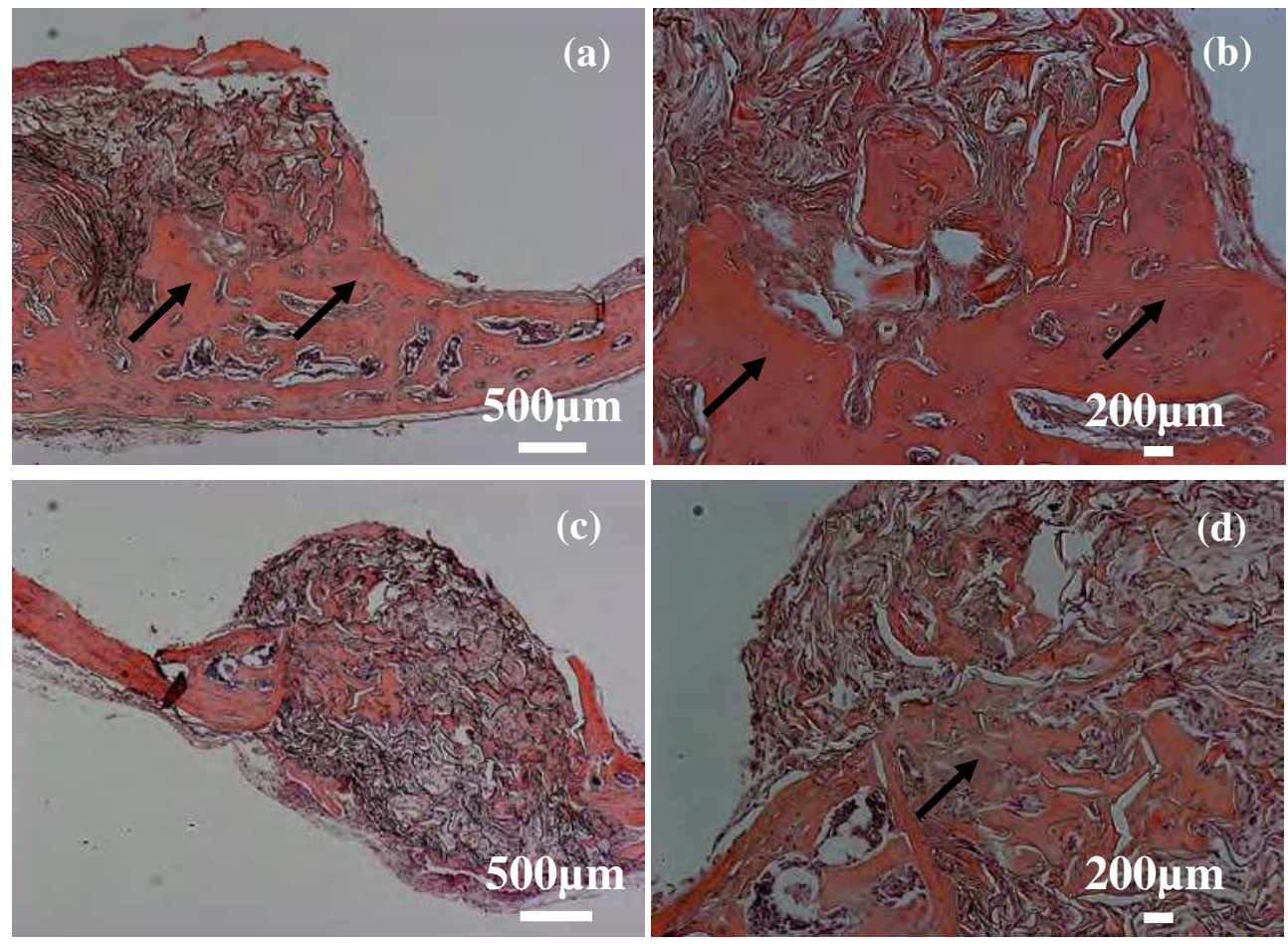

Fig. 13. The in vivo bone formation was evaluated by hematoxylin and eosin ( $\mathrm{H} \& \mathrm{E})$ staining. (a) and (b): MBG/silk; (c) and (d): BG/silk. (b) and (d) are higher magnification images. Arrows point to new formed bone [33].

There are three reasons that best explains why MBG/silk scaffolds have improved newbone formation, compared to BG/silk scaffolds [33]: (1) apatite mineralization plays an important role in bone repair and studies suggest that apatite mineralization of $45 \mathrm{~S} 5$ bioglass [36], A-W bioactive glass ceramics [39] and $\mathrm{CaSiO}_{3}$ ceramics [34,40], is the direct factor influencing the in vivo osteogenesis potential of these materials. In the present study, we show that MBG/silk has a better apatite-mineralization ability than does $\mathrm{BG} /$ silk, leading us to draw the tentative conclusion that this may be one of the most important factors to improve new-bone formation. (2) The faster rate of dissolution and Si ion release of the MBG/silk scaffolds compared to BG/silk scaffolds may enhance newbone formation; this is supported by a study that showed that $\mathrm{CaSiO}_{3}$ ceramics has significantly faster rate of degradation than does $\beta$-tricalcium phosphate ceramics and leads to an improved in vivo osseointegration [34]. It has been reported that Si ions may be associated with the initiation of pre-osseous tissue mineralization, both in periosteal or in endochondral ossification, in the early stages of calcification [41,42]. In vitro studies have 
confirmed that silicon released from the materials results in a significant up-regulation of osteoblast proliferation and gene expression [26,43,44]. The faster rate of degradation may in fact provide the space and environment for matrix deposition and tissue growth [45], and, at the same time, the quicker release Si ions from MBG/silk scaffolds may stimulate the viability of osteoblast around the defects, to the benefit of in vivo osteogenesis. (3) One cannot overlook the beneficial role that the stable $\mathrm{pH}$ environment of MBG/silk scaffolds has on in vivo osteogenesis [46,47].
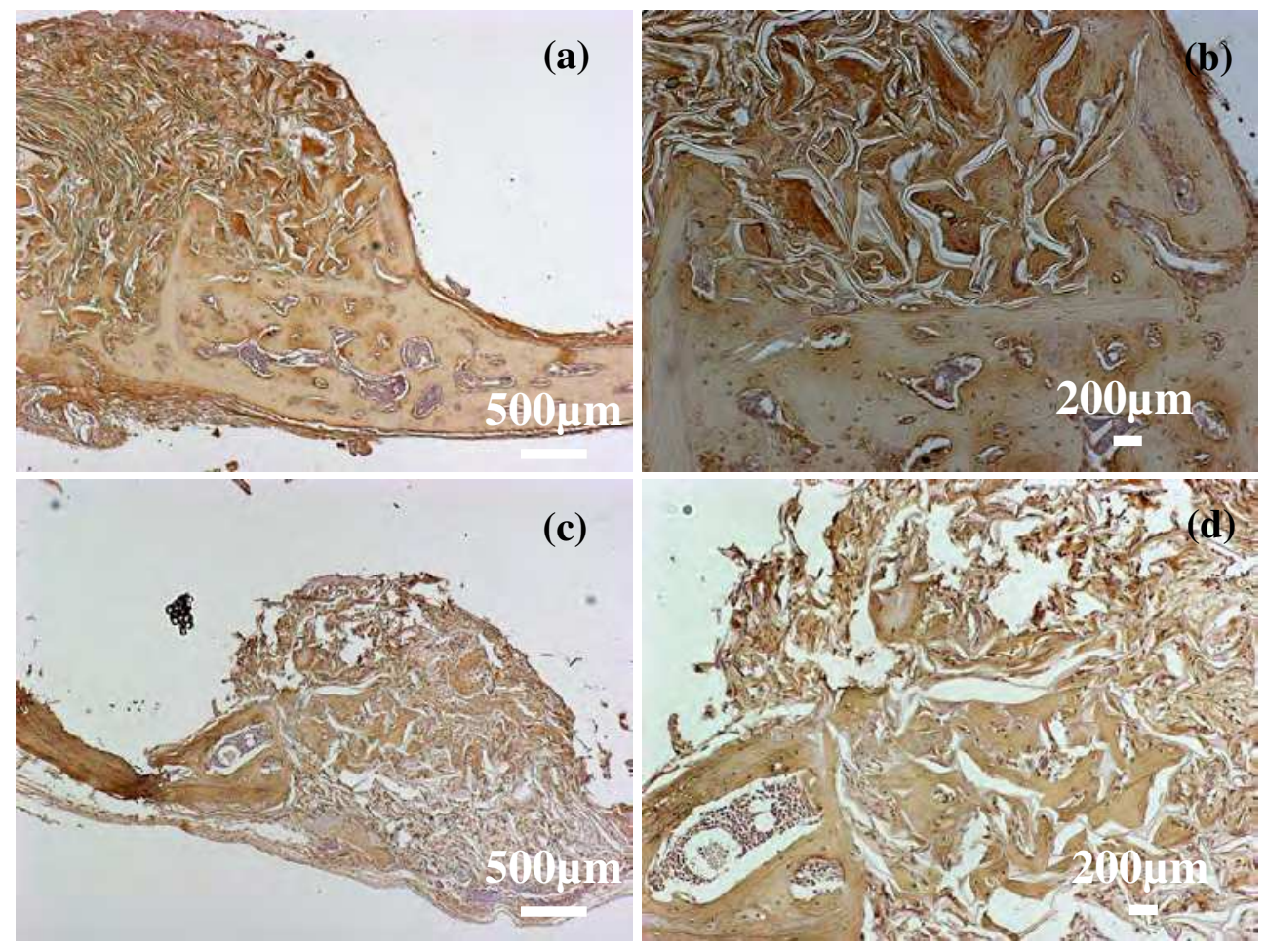

Fig. 14. Immunohistochemical analysis by Collagen I staining on the new bone tissues. (a) and (b): MBG/silk; (c) and (d): BG/silk. (b) and (d) are higher magnification images [33].

\section{Conclusion}

In summary, we have successfully developed scaffolds containing MBG and silk components for the purpose of bone tissue engineering. Two approaches in scaffold fabrication have been investigated, namely silk surface-coating for MBG scaffolds and MBG integrated silk scaffold. 
Porous silk-modified MBG scaffolds with high porosity and large-pore size have been prepared by coating silk on the pore walls surfaces of MBG scaffolds. Silk modification improves the continuity of pore network and mechanical strength of MBG scaffolds, resulting enhanced BMSC proliferation, differentiation and in vivo bone formation.

We have prepared MBG powders-incorporated silk scaffolds and found that MBG can significantly improve the in vitro bioactivity and in vivo osteogenesis of silk scaffolds. MBG/silk scaffolds have the improved physio-chemistry and new-bone formation ability compared to BG/silk scaffolds.

Our study indicates that MBG/silk composite scaffolds, in the forms of silk-modified MBG scaffolds and MBG powder-integrated silk scaffolds, are very promising potential biomaterials for bone repair and regeneration.

\section{Acknowledgment}

The authors would like to acknowledge the support of Vice-chancellor Fellowship (2414020120/07) and BlueBox (241402-0126/07) of Queensland University of Technology and the NHMRC Australia-China Fellowship Scheme,. We also thank Dr Yufang Zhu and A/Prof Yufeng Zhang's for their contributions in this work.

\section{References}

[1] Zhao, D., Feng, J., Huo, Q., Melosh, N., Fredrickson, G.H., Chmelka, B.F. and Stucky, G.D. (1998) Triblock copolymer syntheses of mesoporous silica with periodic 50 to 300 angstrom pores. Science, 279, 548-552.

[2] Lopez-oriega A, Arcos D, Izquierdo-Barb I, Sakamoto Y, Terasaki O and Vallet-Regi, M. (2006) Ordered mesoporous bioactive glasses for bone tissue regeneration. Chem Mater, 18, 3137-3144.

[3] Vallet-Regi, M. (2006) Revisiting ceramics for medical applications. Dalton Transactions, 5211-5220.

[4] Vallet-Regi, M.A., Ruiz-Gonzalez, L., Izquierdo-Barba, I. and Gonzalez-Calbet, J.M. (2006) Revisiting silica based ordered mesoporous materials: medical applications. J Mater Chem, 16, 26-31.

[5] Xia, W. and Chang, J. (2006) Well-ordered mesoporous bioactive glasses (MBG): a promising bioactive drug delivery system. J Control Release, 110, 522-530.

[6] Xia W and Chang, J. (2008) Preparation, in vitro bioactivity and drug release property of well-ordered mesoporous 58 S bioactive glass. J Non-Cryst Solids, 15, 1338-1341.

[7] Wu, C., Ramaswamy, Y., Zhu, Y., Zheng, R., Appleyard, R., Howard, A. and Zreiqat, H. (2009) The effect of mesoporous bioactive glass on the physiochemical, biological and drug-release properties of poly(DL-lactide-co-glycolide) films. Biomaterials, 30, 2199-2208.

[8] Hutmacher, D.W. (2000) Scaffolds in tissue engineering bone and cartilage. Biomaterials, 21, 2529-2543.

[9] Park, S.H., Gil, E.S., Kim, H.J., Lee, K. and Kaplan, D.L. Relationships between degradability of silk scaffolds and osteogenesis. Biomaterials, 31, 6162-6172. 
[10] Wang, Y., Rudym, D.D., Walsh, A., Abrahamsen, L., Kim, H.J., Kim, H.S., Kirker-Head, C. and Kaplan, D.L. (2008) In vivo degradation of three-dimensional silk fibroin scaffolds. Biomaterials, 29, 3415-3428.

[11] Yun, H.S., Kim, S.E. and Hyeon, Y.T. (2007) Design and preparation of bioactive glasses with hierarchical pore networks. Chem Comm, 2139-2141.

[12] Nazarov, R., Jin, H.J. and Kaplan, D.L. (2004) Porous 3-D scaffolds from regenerated silk fibroin. Biomacromolecules, 5, 718-726.

[13] Mandal, B.B. and Kundu, S.C. (2009) Cell proliferation and migration in silk fibroin 3D scaffolds. Biomaterials, 30, 2956-2965.

[14] Zhang, Y., Wu, C., Friis, T. and Xiao, Y. (2010) The osteogenic properties of CaP/silk composite scaffolds. Biomaterials, 31, 2848-2856.

[15] Vepari, C. and Kaplan, D.L. (2007) Silk as a Biomaterial. Prog Polym Sci, 32, 991-1007.

[16] Zhao, J., Zhang, Z., Wang, S., Sun, X., Zhang, X., Chen, J., Kaplan, D.L. and Jiang, X. (2009) Apatite-coated silk fibroin scaffolds to healing mandibular border defects in canines. Bone, 45, 517-527.

[17] Altman, G.H., Diaz, F., Jakuba, C., Calabro, T., Horan, R.L., Chen, J., Lu, H., Richmond, J. and Kaplan, D.L. (2003) Silk-based biomaterials. Biomaterials, 24, 401-416.

[18] Zhu, Y., Wu, C., Ramaswamy, Y., Kockrick, E., Simon, P., Kaskel, S. and Zreiqat, H. (2008) Preparation, characterization and in vitro bioactivity of mesoporous bioactive glasses (MBGs) scaffolds for bone tissue engineering. Micropor Mesopor Mat, 112, 494-503.

[19] Wu, C., Zhang, Y., Zhu, Y., Friis, T. and Xiao, Y. (2010) Structure-property relationships of silk-modified mesoporous bioglass scaffolds. Biomaterials, 31, 3429-3438.

[20] Wu, C., Ramaswamy, Y., Boughton, P. and Zreiqat, H. (2008) Improvement of mechanical and biological properties of porous $\mathrm{CaSiO} 3$ scaffolds by poly(D,L-lactic acid) modification. Acta Biomater, 4, 343-353.

[21] Kim, H.W., Knowles, J.C. and Kim, H.E. (2005) Hydroxyapatite porous scaffold engineered with biological polymer hybrid coating for antibiotic Vancomycin release. J Mater Sci Mater Med, 16, 189-195.

[22] Wu, C., Chang, J., Zhai, W. and Ni, S. (2007) A novel bioactive porous bredigite $\left.\left(\mathrm{Ca}\left({ }_{7}\right) \mathrm{MgSi}{ }_{4}\right) \mathrm{O}(16)\right)$ scaffold with biomimetic apatite layer for bone tissue engineering. J Mater Sci Mater Med, 18, 857-864.

[23] Gibson LJ, A.M. (1999, 429-452.) Cellular solids: structure and properties. 2nd ed. Pergamon, Oxford.

[24] Jongpaiboonkit, L., Franklin-Ford, T. and Murphy, W.L. (2009) Mineral-Coated Polymer Microspheres for Controlled Protein Binding and Release. Adv Mater, 21, 1960-1963.

[25] Kokubo, T. and Takadama, H. (2006) How useful is SBF in predicting in vivo bone bioactivity? Biomaterials, 27, 2907-2915.

[26] Xynos, I.D., Edgar, A.J., Buttery, L.D., Hench, L.L. and Polak, J.M. (2000) Ionic products of bioactive glass dissolution increase proliferation of human osteoblasts and induce insulin-like growth factor II mRNA expression and protein synthesis. Biochem Biophys Res Commun, 276, 461-465. 
[27] Wu, C., Ramaswamy, Y., Soeparto, A. and Zreiqat, H. (2008) Incorporation of titanium into calcium silicate improved their chemical stability and biological properties. $J$ Biomed Mater Res A, 86, 402-410.

[28] John, A., Varma, H.K. and Kumari, T.V. (2003) Surface reactivity of calcium phosphate based ceramics in a cell culture system. J Biomater Appl, 18, 63-78.

[29] Zreiqat, H., Valenzuela, S.M., Nissan, B.B., Roest, R., Knabe, C., Radlanski, R.J., Renz, H. and Evans, P.J. (2005) The effect of surface chemistry modification of titanium alloy on signalling pathways in human osteoblasts. Biomaterials, 26, 7579-7586.

[30] Zhang, F., Zhang, Z., Zhu, X., Kang, E.T. and Neoh, K.G. (2008) Silk-functionalized titanium surfaces for enhancing osteoblast functions and reducing bacterial adhesion. Biomaterials, 29, 4751-4759.

[31] Cai, K., Hu, Y. and Jandt, K.D. (2007) Surface engineering of titanium thin films with silk fibroin via layer-by-layer technique and its effects on osteoblast growth behavior. J Biomed Mater Res A, 82, 927-935.

[32] Cai, K., Yao, K., Lin, S., Yang, Z., Li, X., Xie, H., Qing, T. and Gao, L. (2002) Poly(D,Llactic acid) surfaces modified by silk fibroin: effects on the culture of osteoblast in vitro. Biomaterials, 23, 1153-1160.

[33] Wu, C., Zhang, Y., Zhou, Y., Fan, W. and Xiao, Y. (2011) A comparative study of mesoporous-glass/silk and non-mesoporous-glass/silk scaffolds: physiochemistry and in vivo osteogenesis. Acta Biomater, 7, 2229-2236.

[34] Xu, S., Lin, K., Wang, Z., Chang, J., Wang, L., Lu, J. and Ning, C. (2008) Reconstruction of calvarial defect of rabbits using porous calcium silicate bioactive ceramics. Biomaterials, 29, 2588-2596.

[35] Hench, L.L. (1991) Bioceramics: from concept to clinic. J Am Ceram Soc, 74, 1487-1510.

[36] Hench, L.L. (1998) Biomaterials: a forecast for the future. Biomaterials, 19, 1419-1423.

[37] Hench, L.L. and Wilson, J. (1984) Surface-active biomaterials. Science, 226, 630-636.

[38] Wu, C., Zhang, Y., Ke, X., Xie, Y., Zhu, H., Crowford, R. and Xiao, Y. (2010) Bioactive mesopore-bioglass microspheres with controllable protein-delivery properties by biomimetic surface modification. J Biomed Mater Res A, In Press.

[39] Kokubo T. (1990) Surface chemistry of bioactive glass-ceramics. J Non-Cryst Solids 120, 138-151.

[40] Xue, W., Liu, X., Zheng, X. and Ding, C. (2005) In vivo evaluation of plasma-sprayed wollastonite coating. Biomaterials, 26, 3455-3460.

[41] Carlisle, E.M. (1970) Silicon: a possible factor in bone calcification. Science, 167, 279280.

[42] Schwarz, K. and Milne, D.B. (1972) Growth-promoting effects of silicon in rats. Nature, 239, 333-334.

[43] Valerio, P., Pereira, M.M., Goes, A.M. and Leite, M.F. (2004) The effect of ionic products from bioactive glass dissolution on osteoblast proliferation and collagen production. Biomaterials, 25, 2941-2948.

[44] Wu, C., Chang, J., Ni, S. and Wang, J. (2006) In vitro bioactivity of akermanite ceramics. J Biomed Mater Res A, 76, 73-80.

[45] Burg, K.J., Porter, S. and Kellam, J.F. (2000) Biomaterial developments for bone tissue engineering. Biomaterials, 21, 2347-2359. 
[46] Verrier, S., Blaker, J.J., Maquet, V., Hench, L.L. and Boccaccini, A.R. (2004) PDLLA/Bioglass composites for soft-tissue and hard-tissue engineering: an in vitro cell biology assessment. Biomaterials, 25, 3013-3021.

[47] Putnam, D. (2008) The heart of the matter. Nat Mater, 7, 836-837. 


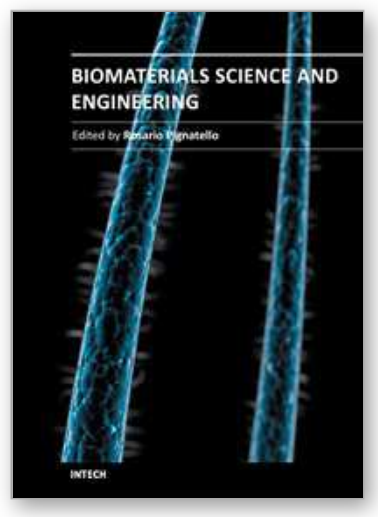

\author{
Biomaterials Science and Engineering \\ Edited by Prof. Rosario Pignatello
}

ISBN 978-953-307-609-6

Hard cover, 456 pages

Publisher InTech

Published online 15, September, 2011

Published in print edition September, 2011

These contribution books collect reviews and original articles from eminent experts working in the interdisciplinary arena of biomaterial development and use. From their direct and recent experience, the readers can achieve a wide vision on the new and ongoing potentials of different synthetic and engineered biomaterials. Contributions were not selected based on a direct market or clinical interest, than on results coming from very fundamental studies which have been mainly gathered for this book. This fact will also allow to gain a more general view of what and how the various biomaterials can do and work for, along with the methodologies necessary to design, develop and characterize them, without the restrictions necessarily imposed by industrial or profit concerns. The book collects 22 chapters related to recent researches on new materials, particularly dealing with their potential and different applications in biomedicine and clinics: from tissue engineering to polymeric scaffolds, from bone mimetic products to prostheses, up to strategies to manage their interaction with living cells.

\title{
How to reference
}

In order to correctly reference this scholarly work, feel free to copy and paste the following:

Chengtie Wu and Yin Xiao (2011). Mesopore Bioglass/Silk Composite Scaffolds for Bone Tissue Engineering, Biomaterials Science and Engineering, Prof. Rosario Pignatello (Ed.), ISBN: 978-953-307-609-6, InTech, Available from: http://www.intechopen.com/books/biomaterials-science-and-engineering/mesopore-bioglasssilk-composite-scaffolds-for-bone-tissue-engineering

\section{INTECH}

open science | open minds

\section{InTech Europe}

University Campus STeP Ri

Slavka Krautzeka 83/A

51000 Rijeka, Croatia

Phone: +385 (51) 770447

Fax: +385 (51) 686166

www.intechopen.com

\section{InTech China}

Unit 405, Office Block, Hotel Equatorial Shanghai

No.65, Yan An Road (West), Shanghai, 200040, China

中国上海市延安西路65号上海国际贵都大饭店办公楼 405 单元

Phone: +86-21-62489820

Fax: $+86-21-62489821$ 
(C) 2011 The Author(s). Licensee IntechOpen. This chapter is distributed under the terms of the Creative Commons Attribution-NonCommercialShareAlike-3.0 License, which permits use, distribution and reproduction for non-commercial purposes, provided the original is properly cited and derivative works building on this content are distributed under the same license. 